\title{
$\mathrm{DEA}$-마코위츠 결합 모형을 이용한 건설업종 투자 전략
}

\author{
유재필 ${ }^{1}$, 신현준 $^{1^{*}}$ \\ ${ }^{1}$ 상명대학교 경영공학과
}

\section{An Investment Strategy for Construction Companies using DEA-Markowitz's Model}

\author{
Jaepil Ryu ${ }^{1}$ and Hyun Joon Shin ${ }^{1^{*}}$ \\ ${ }^{1}$ Dept. of Management Engineering, Sangmyung University
}

\begin{abstract}
요 약 본 연구에서는 KOSPI와 KOSDAQ에 상장된 건설 기업을 대상으로 효율적인 포트폴리오를 구성방안을 제시 한다. 이를 위해 한국거래소(KRX)에서 구분하는 건설 업종을 DEA(Data Envelopment Analysis) 기법을 이용하여 기업 효율성 분석을 실시하고 효율성이 우수한 기업들을 대상으로 마코위츠 모형을 통해 포트폴리오를 구성한다. 본 연구 에서 제안한 포트폴리오 구성 방안의 성능 실험을 위해 KOSPI와 KOSDAQ에 상장된 53개의 기업의 주식을 대상으 로 5년 (2007 2011) 동안 매해 포트폴리오를 구성하였고 각각의 포트폴리오 수익률을 경영 효율성을 고려하지 않고 구성한 포트폴리오 및 벤치마크 수익률과 비교·분석을 통해 그 우수성을 입증하였다.
\end{abstract}

\begin{abstract}
This paper proposes an efficient portfolio selection methodology for the listed construction corporations in KOSPI and KOSDAQ. For the construction industrial sector classified by KRX(Korea Exchange), the proposed method carries out an efficiency analysis using DEA (Data envelopment analysis) approach and for the efficient corporations filtered by DEA, construct portfolio using Markowitz's Model. In order to show the effectiveness of the proposed method, we constructed annually portfolios for 5 years (2007-2011) out of 53 listed corporations in KOSPI and KOSDAQ, and proved that our portfolios are superior to benchmark portfolios in terms of rate of returns.
\end{abstract}

Key Words : Construction companies, DEA, KOSPI, Portfolio selection, Markowitz's portfolio model

\section{1. 서론}

경제 산업의 기반에 있어서 건설업종은 매우 중요한 산업에 속해있다. 경제적 활동에 필요한 원재료를 얻고 공장과 건물 등을 지으면서 경제의 순환은 시작된다. 또 한 조선업, 운송업, 에너지업, 화학업, 철강업, 금융업 등 대부분의 업종은 건설업에 의해 마련된 기반 위에서 확 장이 된 업종이다. 더 나아가 주거시설, 상업시설, 공공시 설 등 인간의 삶과 밀접한 연관을 갖고 있다. 따라서 경 기 상황에 가장 빠르고 민감하게 반응을 하는 특징을 가 진 업종이 건설업종이다. 예컨대 2008년도에 발생한 서 브프라임 모기지 금융위기(subprime mortgage crisis)는
미국은 물론 국내 주택 시장에 악영향을 가져왔으며 이 는 전반적인 경제 산업의 침체를 초래하였다.

그러나 최근 미국의 전미부동산건설협회(National Association of Home Builders; NAHB)의 주택시장 지수 가 2012년부터 상승하고 있고, 주택 가격의 상승과 함께 주택 판매 건도 점차적으로 개선되고 있다. 2012년 7월 기존 주택 판매 건수가 447만호를 기록하며 전월에 기록 한 437만호를 약 10 만호 가량 상회한 것으로 나타났다. 2010년 6월 주택 판매 건이 약 300만호 초반을 기록한 이래로 현재까지 꾸준히 판매 건 수가 증가하고 있는 추 세이다.

최근 정부는 국내 건설업에 대한 지원을 확대하였다.

본 연구는 2012년도 상명대학교 교내연구비 지원을 받아 이루어졌음.

${ }^{*}$ Corresponding Author : Hyun Joon Shin (Sangmyung University)

Tel: +82-10-7148-6786 email:hjshin@smu.ac.kr

Received October 31, 2012 Revised November 14, 2012 Accepted February 6, 2013 
국토해양부에서는 태국에서 발주 계획되어 있는 대규모 프로젝트를 국내 건설업체들이 수주할 수 있는 방안을 마련 중이다. 특히 이외에도 2013년 국제입찰 추진 예정 인 약 100 억 달러 규모의 태국 고속 철도 사업과 2030년 까지 총 $55,000 \mathrm{MW}$ 규모 발주 계획 예정인 발전소 프로 젝트 입찰에서도 국내업체들의 참여할 계획이다.

건설업은 1966년 첫 해외 수주를 시작한 이후, 2012년 5 월 누적 해외 수주가 약 5,000억 달러를 기록하였다. 현 재의 건설업 기업은 국내뿐만 아니라 해외로 사업을 확 장하고 있다. 특히 2012년 상반기 전체 해외 수주 약 110 억 달러 중 약 $57 \%$ 인 약 62 억 달러를 중동 국가에서 수 주하였으며, 누적 해외 수주 약 5,000억 달러 중 약 $60 \%$ 인 약 3,000 억 달러를 중동에서 수주하였다.

건설 산업의 상장된 기업의 시가총액의 합은 약 43 조 원으로 국내 주요 업종 중에서 5 번째로 규모가 크다. 그 림 1은 외환자본의 개방 이후인 2002년부터 2011년까지 의 KOSPI와 KOSDAQ에 상장된 건설 기업의 시가총액 합을 나타낸다.

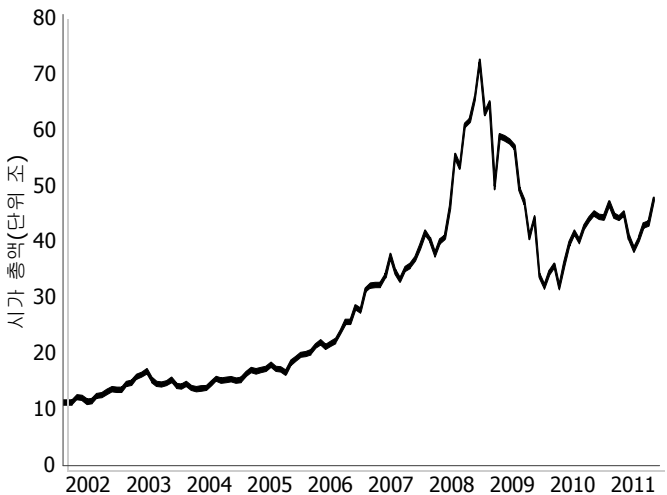

[Fig. 1] Market capitalization of construction companies

2002년 이후 건설 기업은 급속도로 성장하여 2008년 9월에는 건설 기업의 시가총액이 70 조원을 돌파하였다. 그 이후 서브프라임 모기지와 한국의 주택 가격 안정화 정책 등으로 인해서 2009년 말에는 40조원 이하로 폭락 하였다. 최근 건설 서비스 지수와 정부의 지원 정책 등으 로 인해서 건설 기업의 시가총액은 증가 추세를 보인다.

이처럼 국내 금융 시장에서 큰 비중을 차지하고 있는 건설업은 2011년 12월 기준으로 우선주와 상장지수펀드 (Exchange Traded Funds; 이하 ETF) 등을 제외하고 56개 의 건설 관련 기업이 증권 시장에 상장되어 있다.

또한 KODEX 건설 $\mathrm{ETF}$ 상품이 2009년 말에 한국거래 소(KRX)에 상장함으로써 건설 산업에 대한 투자가 증가
하고 있다. 그러나 건설 업종만으로 구성된 KODEX 건 설 상품은 투자 종목 선택과 비중을 결정하는데 있어서 시가총액 가중 방식을 이용하기 때문에 기업의 성장성과 경영 효율성 등을 고려할 수 없다는 한계점이 있다. 실제 로 KODEX 건설 상품의 상장 시점을 기준으로 벤치마크 대비 약 $2.81 \%$ 만큼의 초과수익률만을 기록하고 있다.

본 논문에서는 정량적인 포트폴리오 구성을 위한 방법 론을 DEA(Data envelopment analysis) 모형과 마코위츠 포트폴리오 선정 모형(Markowitz's Portfolio Selection Model)을 이용하여 수립하고자 한다.

일반적인 투자자들은 투자 결정을 그들의 심리나 투자 에 따른 변수를 고려하여 정성적인 의사결정을 내려 포 트폴리오를 구성한다. 하지만 정성적인 의사결정 보다 구 성된 종목들 간의 상관관계를 최소화할 수 있는 마코위 츠 포트폴리오 선정 모형을 활용하여 정량적인 의사결정 을 내려 포트폴리오를 구성하는 것이 투자자에게 더 유 리하다. 그러나 마코위츠 포트폴리오 선정 모형은 종목들 의 과거 주가 데이터에만 의존하기 때문에 기업들의 경 영 효율성을 고려할 수 없다는 단점을 보완하기 위해서 기업의 경영 효율성을 고려하여 포트폴리오를 구성하기 위해 경영과학 분야의 DEA 기법과 마코위츠 모형을 이 용한 정량적인 포트폴리오 구성 방법론을 제시하고자 한다.

따라서 본 논문에서는 마코위츠 모형만을 이용한 포트 폴리오 구성 전략과 $\mathrm{DEA}$ 와 마코위츠 모형을 결합한 포 트폴리오 구성 전략을 제시하고 벤치마크 수익률과 비교 분석하여 그 우수성을 입증하고자 한다.

본 논문은 다음과 같이 구성된다. 2장에서는 DEA 기 법과 마코위츠 모형을 결합한 포트폴리오 구성 전략에 대해 설명한다. 3장에서는 KOSPI와 KOSDAQ에 상장된 건설 기업들의 주가와 재무 데이터를 이용하여 구성한 포트폴리오 수익률과 성과 분석을, 마지막으로 4장에서 는 결론을 기술한다.

\section{2. 포트폴리오 선택 전략}

자산의 위험을 최소화하기 위해서 구성하는 포트폴리 오는 체계적인 위험(systemic risk)과 비체계적인 위험 (unsystematic risk)에 노출된다. 체계적인 위험, 즉 경기 의 침체와 시장의 불안으로 인해 피할 수 없는 위험과는 다르게 비체계적인 위험은 금융 시장과는 무관하게 계별 종목들의 변동 요인에 의해 발생하기 때문에 효율적인 포트폴리오를 구성함으로써 위험을 최소화할 수 있다[3].

일반적으로 포트폴리오를 구성하기 위해서 구성된 종 목들 간의 상관관계를 최소화할 수 있는 마코위츠 모형 
을 활용한다. 그러나 마코위츠 모형은 종목들의 과거 주 가에만 의존하여 포트폴리오를 구성하기 때문에 기업들 의 경영 효율성 등을 고려할 수 없다는 한계점이 있다.

따라서 본 장에서는 기업의 경영 효율성을 고려하여 포트폴리오를 구성하기 위해 경영과학 분야의 DEA 기법 과 마코위츠 모형을 결합한 포트폴리오 구성 방법론을 제시하고자 한다.

\subsection{DEA 기법을 이용한 경영 효율성 평가}

자료포락분석(Data Envelopment Analysis; 이하 DEA) 은 1978년 Charnes, Cooper \& Rhodes에 의해 제안되어 복수투입과 복수산출에 관한 비율모형으로 의사결정 대 안에 대한 효율성 정도를 파악하는데 매우 유용하다. 이 기법은 투입요소와 산출요소를 사용하여 동일하거나 매 우 유사한 기능을 수행하는 의사결정단위(Decision Making Unit; 이하 DMU) 또는 조직단위의 상대적 효율성을 측 정하고 평가하는데 사용 할 수 있는 방법론이다.

DEA 모형을 통한 효율성 평가를 실시함에 있어서 가 장 중요한 요소 중 하나는 투입 및 산출요소의 선정에 있 다. 본 연구에서는 선행연구를 통해서 투입 및 산출요소 를 자산총계, 매출원가 판관비 그리고 매출액으로 정의하 였다.

경영 효율성을 분석할 수 있는 $\mathrm{DEA}$ 모형에는 CCR(Charnes-Cooper-Rhodes), BCC(Banker- Charnes-Cooper), 가변형 모형(additive model), 슬랙 중심 측정모형 (slacks-based measure) 등 많은 종류가 개발되었다[4]. 본 논문에서는 규모수익성(Return to Scale; RTS)이 일정하 지 않다고 가정한 $\mathrm{BCC}$ 모형을 기반으로 실험을 실시하 고자 하며 투입중심 $\mathrm{BCC}$ 모형을 선형계획모형으로 정리 하면 다음과 같다[6].

$$
\begin{array}{ll}
\text { Minimize } & \eta \\
\text { subject to } & \eta x_{0}-X \lambda \geq 0 \\
& y_{0}-Y \lambda \leq 0 \\
& e \lambda \geq 1 \\
& \lambda \geq 0
\end{array}
$$

Notations :

$\eta \quad \mathrm{DMU}_{0}$ 의 $\mathrm{BCC}$ 효율성

e 1로만 이뤄진 벡터

$x_{0}, y_{0} \mathrm{DMU}_{0}$ 의 투입물과 산출물 벡터

$X, Y$ 전체 $\mathrm{DMU}$ 들의 투입물과 산출물 행렬

$\lambda$ 가중치 열 벡터
$\mathrm{BCC}$ 모형은 $\mathrm{CCR}$ 모형에서 규모의 수익 불변이라는 가정의 한계점을 보완하고 $\mathrm{DMU}$ 에 대한 참조 집합의 크 기를 1 로 제한하는 불록성 조건을 추가하였다.

본 연구에서는 경영 효율성이 우수한 건설 기업들을 대상으로 포트폴리오를 구성하기 위해 위 식 (1) (5)를 바탕으로 DEA 경영 효율성 분석을 통해 효율성 값이 0.9 이상인 기업들을 선정한다.

\section{2 마코위츠 모형을 이용한 포트폴리오 선택 전략}

마코위츠 포트폴리오 선정모형은 비선형계획모형 (nonlinear programming model)으로 일정한 수익률 제약 하에 자산 간의 상관계수가 낮은 종목을 포트폴리오에 포함함으로써 안정적이고 효율적 포트폴리오를 구성하는 것을 기본 개념으로 한다[5]. 마코위츠 모형은 위험의 수 준을 나타내는 개별 종목 수익률들 간의 공분산을 최소 화하는 것을 목적함수로 한다. 더불어 기본적으로 '공매 도가 존재하지 않는다.'는 가정 하에 투자자가 요구하는 최소기대수익률을 달성해야 하고, 투자가 가능한 금액을 모두 포트폴리오에 투자해야 한다는 제약조건이 따른다 [3]. 본 논문에서 사용하는 마코위츠 모형은 다음과 같다.

$$
\begin{array}{ll}
\text { Minimize } & \sum_{i=1}^{N} \sum_{j=1}^{N} w_{i} w_{j} \sigma_{i j} \\
\text { subject to } & \sum_{j=1}^{N} \mu_{j} w_{j} \geq K \\
& \sum_{j=1}^{N} w_{j}=1
\end{array}
$$

Notation :

$N$ 전체 종목 수

$\mu_{j}$ 주식 $j$ 의 평균수익률 $(j=1,2, \cdots, N)$

$\sigma_{i j}$ 주식 $i$ 수익률과 주식 $j$ 수익률 간의 공분산

$K$ 포트폴리오에 요구되는 최소 기대수익률

$w_{j}$ 포트폴리오에서 주식 $j$ 의 구성 비율

식 (6)은 목적함수로써 포트폴리오를 구성할 종목들 간의 수익률의 공분산을 최소로 하기 위한 식이다. 즉 포 트폴리오에 투자 위험을 최소로 할 수 있는 종목들을 포 함시킴과 동시에 식 (7)에서는 기대수익률을 $K$ 이상으로 제약한다. 식 (8)은 투자 원금의 모두를 포트폴리오에 투 자한다는 제약식이다.

본 장에서 설명한 DEA 기법과 마코위츠를 결합한 포 트폴리오 구성 전략을 순서도로 정리하면 그림 2와 같다. 


\section{3. 실험 결과 및 분석}

\section{1 실험 데이터 및 실험 계획}

포트폴리오 구성을 위해 2006년부터 2011년까지 $\mathrm{KOSPI}$ 와 KOSDAQ에 상장된 53개의 건설업 종목을 선 정하였다. 포트폴리오 구성 기간은 2007년부터 2011년까 지이며 표 1 은 본 연구의 실험 데이터와 실험 계획에 대 한 설명이다.

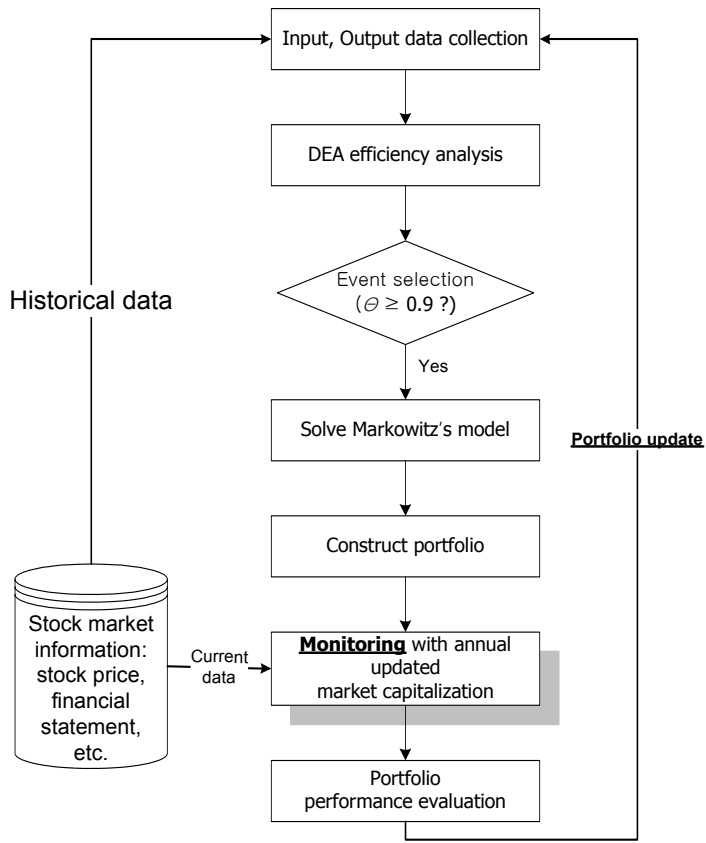

[Fig. 2] Portfolio selection strategy

[Table 1] Experimental data and design

\begin{tabular}{|c|c|}
\hline 대상 & $\begin{array}{c}\text { KOSPI, KOSDAQ에 상장된 } \\
\text { 53개의 건설 기업 }\end{array}$ \\
\hline 기간 & $\begin{array}{c}\text { 2007년부터 2011년까지 } \\
\text { (전년도 12월 31일부터 } \\
\text { 홀해 12월 31낄까지) }\end{array}$ \\
\hline 평가 주기 & $\begin{array}{c}1 \text { 회/년 } \\
\text { (연 초 포트폴리오 구성 후, 연말 평가) }\end{array}$ \\
\hline 성과 측정 & $\begin{array}{c}\text { 벤치마크 대비 포트폴리오 수익률, } \\
\text { Sharpe Ratio, 젠센의 알파, IR }\end{array}$ \\
\hline 자료 수집 & 이데일리 MARKETPOINT \\
\hline
\end{tabular}

본 연구에서 제시하는 DEA기법을 이용한 포트폴리오 구성 방안은 전년도 수집 요인을 바탕으로 다음년도 포 트폴리오를 구성하는 방식으로 실험을 실시하였다. 예컨
대 2007년 초에 포트폴리오를 구성하기 위해서 2006년 한 해 동안의 투입 요소와 산출 요소를 이용하여 경영 효 율성을 평가하였다.

본 연구에서는 마코위츠 모형을 통해 구성한 포트폴 리오와 DEA와 마코위츠 모형을 결합하여 구성한 포트폴 리오를 동일한 기간만큼의 벤치마크 수익률과 비교 분석 하였다. 편의를 위해 마코위츠 모형을 이용한 포트폴리오 구성 전략을 $P M_{M Q}$ 로 $\mathrm{DEA}$ 와 마코위츠 모형을 결합한 포트폴리오 구성 전략을 $P M_{D E A \_M Q}$ 로 표현하였다.

[Table 2] Comparison of rate of return by year

\begin{tabular}{|c|c|c|c|}
\hline 년도 & $P M_{D E A \_M Q}$ & $P M_{M Q}$ & 벤치마크 \\
\hline 2007 & $127 \%$ & $122 \%$ & $83 \%$ \\
\hline 2008 & $-26 \%$ & $-36 \%$ & $-34 \%$ \\
\hline 2009 & $7 \%$ & $-20 \%$ & $45 \%$ \\
\hline 2010 & $83 \%$ & $39 \%$ & $33 \%$ \\
\hline 2011 & $-2 \%$ & $15 \%$ & $-26 \%$ \\
\hline
\end{tabular}

\section{2 포트폴리오 수익률 분석}

표 2는 2006년부터 2010년까지 본 연구에서 제시하는 $P M_{D E A} M Q$ 수익률과 비교 대상인 $P M_{M Q}$ 수익률, 그리 고 동일 기간 벤치마크 수익률을 비교하고 있다. 포트폴 리오의 수익률은 시가총액을 기준으로 가중 평균을 하여 산출하였고, 벤치마크는 포트폴리오 구성 및 갱신 시점과 동일한 기간으로 53 개의 모든 건설 기업에 대한 수익률 의 평균을 사용하였다. 2011년을 제외하고 $P M_{D E A} M Q$ 방법론의 포트폴리오 수익률이 $P M_{M Q}$ 방법론의 수익률 보다 우수한 것을 볼 수 있다. 또한 $P M_{D E A ~ M Q}$ 방법론의 수익률이 2009년도를 제외하고 벤치마크 수익률에 비해 우수한 결과를 나타낸다. 2008년도에는 서브프라임 모기 지로 인한 금융 시장의 불황으로 수익률이 전반적으로 저조하지만 같은 년도의 $P M_{D E A} M Q$ 방법론의 수익률은 $-26 \%$ 로써 $P M_{M Q}$ 방법론의 수익률인 $-36 \%$ 그리고 벤 치마크 수익률 $-34 \%$ 에 비해서 손실 규모면에서 적은 것을 알 수 있다.

그림 3는 표 2에서 $P M_{D E A \_M Q}$ 의 포트폴리오 수익률 과 $P M_{M Q}$ 의 포트폴리오 수익률, 그리고 벤치마크 수익 률을 연도별로 나타낸 그림이다. 앞서 기술한 바와 같이 2009년도를 제외하고는 $P M_{D E A \_M Q}$ 의 수익률이 벤치마 크 수익률보다 더 우수한 것을 알 수 있었다. 또한 금융 시장의 불황이었던 2008년에는 $P M_{D E A-M Q}$ 의 수익률이 
벤치마크 수익률에 비해 약 $8 \%$ 더 적은 손실을 보았음을 알 수 있다.

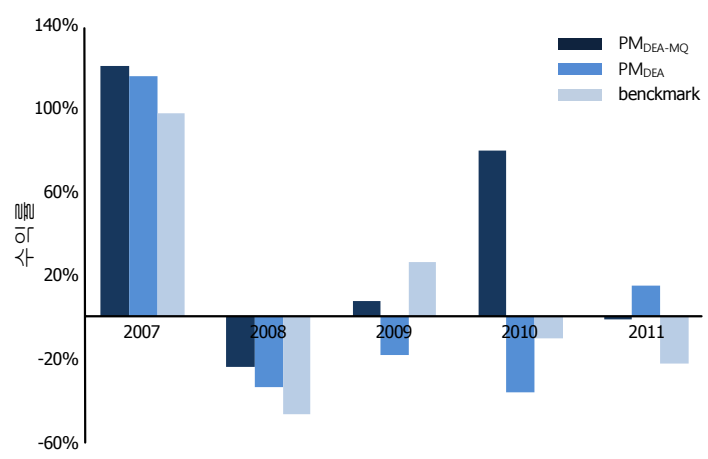

[Fig. 3] Comparison between $P M_{D E A \_M Q}$ and benchmarks

\section{3 포트폴리오 성과 측정}

일반적으로 포트폴리오 성과 측정을 위한 도구로 Sharpe Ratio와 젠센의 알파 그리고 IR이 있다. Sharpe Ratio는 포트폴리오의 위험 1 단위에 대한 초과 수익의 정도를 나타내는 지표, 즉 초과 수익이 얼마인가를 측정 하는 지표이고 모형은 식(9)와 같다.

$$
\text { Sharpe Ratio }=\frac{R_{i}-R_{f}}{\sigma_{i}}
$$

\section{Notations :}

$R_{i} \quad$ 포트폴리오 $i$ 의 수익률

$R_{f} \quad$ 무위험 수익률(국고채 3년 만기)

$\sigma_{f} \quad$ 포트폴리오 $i$ 의 표준편차

젠센의 알파는 포트폴리오의 수익률이 균형 상태에서 의 수익률보다 얼마나 높은지를 나타내는 지표, 즉 포트 폴리오 수익률에서 기대 수익률을 뺀 값을 의미하며 모 형은 식(10)과 같다.

젠센의 알파 $=\left(R_{i}-R_{f}\right)-b_{p}^{*}\left(K_{i}-R_{f}\right)$

Notations :

$b_{p} \quad$ 포트폴리오의 베타

$K_{i} \quad$ 시장 수익률

그리고 IR은 포트폴리오 관리자의 능력을 측정할 수 있는 지표로 포트폴리오의 초과 수익률을 추적 오차로
나눈 값을 말하며 RVR(Reward-to-Variability Ratio)라고 도 부른다. 세 가지 모두 측정 된 결과 값이 클수록 투자 성과가 우수하다고 할 수 있으며 IR의 경우에는 실무적 으로 미국에서는 $50 \%$ 이내인 경우에 '우수'한 것으로 평 가한다. IR의 산출 모형은 식(11)과 같다.

$$
I R=\frac{\left(R_{i}-K_{i}\right)}{T e}
$$

Notations :

$T e$ 추적 오차의 표준편차

표 3는 $P M_{D E A_{-} M Q}$ 방법론과 $P M_{M Q}$ 방법론에 의해 구성된 포트폴리오의 성과를 측정한 결과 값을 나타내고 있다. Sharpe Ratio와 젠센의 알파 그리고 IR 모두 성과 측정값이 높을수록 우수한 포트폴리오라고 정의한다. $P M_{D E A_{-} M Q}$ 의 포트폴리오가 $P M_{M Q}$ 포트폴리오의 성과 에 비해 월등히 우수한 것을 볼 수 있다.

[Table 3] Portfolio Performance Measurement

\begin{tabular}{|c|c|c|c|}
\hline & $\begin{array}{c}\text { Sharpe } \\
\text { Ratio }\end{array}$ & $\begin{array}{c}\text { 젠센의 } \\
\text { 알파 }\end{array}$ & IR \\
\hline$P M_{D E A \_M Q}$ & $166 \%$ & $20 \%$ & $32 \%$ \\
\hline$P M_{M Q}$ & $45 \%$ & $1 \%$ & $-1 \%$ \\
\hline
\end{tabular}

\section{4. 결론}

본 연구에서는 $\mathrm{KOSPI}$ 와 $\mathrm{KOSDAQ}$ 에 상장된 기업을 대상으로 DEA기법을 이용하여 건설 기업들의 경영 효율 성이 우수한 기업들을 선정하고, 선정된 기업들에 대해서 마코위츠 모형을 이용하여 포트폴리오를 구성하는 2단계 방안을 제시하였다. 이를 통해 기존 과거 데이터에만 의 존하는 마코위츠 모형의 한계점을 보완하고 포트폴리오 의 수익률을 높일 수 있었음을 실험을 통해 입증하였다. 특히 기업의 경영 효율성을 고려한 포트폴리오 구성 방 안은 경영 효율성이 부실한 기업을 포트폴리오 구성 조 건에서 제외시켜줌으로써 기존의 마코위츠 포트폴리오 구성 방안보다 수익률과 포트폴리오 성과 측정에 있어서 우수한 결과를 보인다는 것을 알 수 있었다. 또한 포트폴 리오 구성 전략을 위해 DEA 및 마코위츠 모형 등을 이용 한 경영과학적 접근 방법은 투자관리 및 분석에 있어 정 량적인 판단을 지원하므로 금융 기관의 펀드 운용 시 유 용한 지표로 사용될 수 있을 것으로 기대한다[6]. 


\section{Reference}

[1] Chang, Jo Young, "Study on Logistic Efficiency of Third Party Logistic by DEA-AHP method", The Graduate School, Yonsei University, 2008.

[2] Da-Young Choi, Beum Jun Ahn, Hyun Joon Shin, "Portfolio Selection Strategy with Consideration of Growth Potential of Corporations", The Korea Academia-Industrial cooperation Society, Vol.12, No.9, pp.3849-3855, 2011.

DOI: http://dx.doi.org/10.5762/KAIS.2012.13.2.878

[3] Jae Pil Ryu, "A Study on Optimizing Portfolio Management using Inventory Control Methodology", The Graduate School, Sangmyung University, 2011.

[4] JongKi Kim, DaYeon Kang, "Measuring Efficiency of Korean Apartment Construction Firms using DEA", The Korea Contents Association, Vol.8, No.7, pp.201-207, 2008.

DOI: http://dx.doi.org/10.5392/JKCA.2008.8.7.201

[5] Markowitz, H. M. (1952), Portfolio Selection, Journal of Finance, 7(1), 77-91.

DOI: http://dx.doi.org/10.2307/2975974

[6] Min Son, Hyun Joon Shin, "An Efficient Portfolio Selection Methodology using DEA Approach", The Korea Academia-industrial cooperation Society, Vol.13, No.4, pp.1551-1556, 2012.

DOI: http://dx.doi.org/10.5762/KAIS.2012.13.4.1551

[7] Myung-Hee Chang, "Relative Efficiency of Korea Trucking Transport Business Using DEA Model”, The Korea Contents Association, Vol.10, No.12, pp.328-341, 2010

DOI: http://dx.doi.org/10.5392/JKCA.2010.10.12.328

\section{유 재 필(Jae Pil Ryu)}

[정회원]

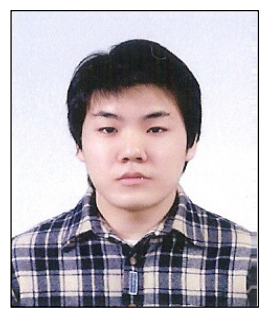

- 2009년 2월 : 상명대학교 산업정 보시스템공학과(공학사)

- 2011년 2월 : 상명대학교 경영공 학과(경영공학석사)

- 2011년 3월 현재 : 상명대학교 경영공학과 박사과정

\section{신 현 준(Hyun Joon Shin)}

[종신회원]

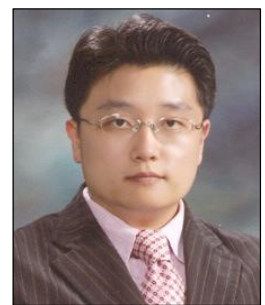

- 1995년 2월 : 고려대학교 산업공 학과(공학사)

- 1997년 2월 : 고려대학교 산업공 학과(공학석사)

- 2002년 2월 : 고려대학교 산업공 학과(공학박사)

- 2002년 5월 2004년 4월 : 미국 Texas A\&M대학교 연구원

- 2004년 6월 2005년 2월 : (주)삼성전자 책임연구원

- 2005년 3월 현재 : 상명대학교 경영공학과 부교수

<관심분야>

금융공학, 최적화, 생산관리, 공급사슬망관리

<관심분야>

금융공학, 생산관리 